\title{
PEMILIHAN PRIORITAS PROGRAM KERJA DENGAN MENGGUNAKAN METODE ANALYTICAL HIERARCHY PROCESS PADA PT. GARUDA INDONESIA CARGO
}

\author{
Dimas Novrisal \\ Universitas Mercu Buana \\ Fakultas Teknik, Program Studi Tehnik Industri \\ Email : dimasnovrisal@yahoo.com
}

\section{Farah Almira}

Institut Ilmu Sosial dan Manajemen Stiami

Fakultas Ilmu Sosial dan Manajemen, Program Studi Manajemen Logistik

Email : farah_brune1@ymail.com

\section{Eva Febrianty}

Universitas Mercu Buana

Fakultas Teknik, Program Studi Tehnik Industri

Email : evafebriantypurnama@gmail.com

\section{ARTICLE INFO}

Keywords:

Work Program Priority, Deliver Goods, AHP

\section{ABSTRACT}

Company is required to compete and being innovated to carry out work program strategies in order to improve the service quality while deliver goods to consumers. Due to limited resources, companies need to prioritize work programs based on existing criteria. The purpose of this study is the selection of work program priorities using the analytical hierarchy process method at PT. Garuda Indonesia Cargo. This research begins with determining the criteria and alternatives that are carried out for making questionnaires, then distributing questionnaires to get priority criteria and alternatives using the AHP method. The results of data processing using the Analytical Hierarchy Process (AHP) method obtained the sequence results from each of the highest to lowest criteria and the highest weighted results were the quality criteria with the final weight value 0.71 after that followed the profit criteria with the final weight 0.29 . After obtained the heightened criteria, the optimal alternative selected is Equipment with a weight value of 0.46 , and followed by HR with a weight value of 0.38 , then Infrastructure with a final weight value of 0.16 .

\section{PENDAHULUAN}

Industri jasa saat ini mengalami perkembangan yang sangat pesat seiring dengan kebutuhan masyarakat akan berbagai jenis jasa dalam berbagai bidang kehidupan. Industri jasa yang sangat dibutuhkan saat ini salah satunya adalah jasa pengiriman barang. Tujuan dari perusahaan jasa 
pengiriman barang adalah memberikan kualitas pelayanan yang tepat, cepat dan efisien dalam pengiriman barang kepada konsumennya. Evaluasi terhadap kualitas pelayanan layaknya terus dipelajari untuk memberikan pelayanan yang baik.

Kualitas pelayanan yang baik akan memberikan kepuasan kepada konsumen dan berdampak positif terhadap perusahaan itu sendiri. PT. Garuda Indonesia Cargo memahami akan pentingnya pelayanan yang baik dan tepat waktu kepada konsumen. Permasalahan yang ada pada PT. Garuda Indonesia Cargo adalah beberapa program kerja yang tidak berjalan dengan baik dikarenakan terbatasnya SDM, dan peralatan sehingga mengakibatkan penurunan kualitas pelayanan yang akhirnya berdampak pada menurunnya kepuasan konsumen.

Dengan keterbatasan sumber daya perusahaan, maka dibutuhkan prioritas dalam memilih program kerja yang harus dilakukan terlebih dahulu. Manajemen harus memilih program kerja mana yang harus dilaksanakan agar memberi manfaat yang lebih baik bagi perusahaan. Berdasarkan latar belakang tersebut, maka penulis tertarik untuk menulis penelitian dengan judul "Pemilihan Prioritas Program Kerja Dengan Menggunakan Metode Analytical Hierarchy Process Pada PT.Garuda Indonesia Cargo".

\section{TINJAUAN PUSTAKA}

Metode AHP (Saaty, 1980), dikembangkan sebagai pendekatan dalam mengambil keputusan yang yang melibatkan banyak kriteria. AHP dirancang untuk membantu pembuat keputusan memilih yang berdasarkan evaluasi alternatif terhadap beberapa kriteria yang bersifat kualitatif atau tidak dapat langsung diukur. (Nakatani, 2011)

Penulis Kustian Nunu (2016), menggunakan metode AHP dalam penentuan pemilihan jasa pengiriman barang transaksi $E$-Commerce online. Hasil yang diperoleh bahwa jasa pengiriman JNE banyak dipilih oleh sebagian besar pengusaha bisnis online untuk konsumen dalam pengiriman barang. Kriteria yang digunakan adalah kualitas pelayanan, kenyamanan, keamanan, kriteria promo dan harga.

Penelitian lainnya yang menggunakan AHP sebagai metode penelitiannya adalah Bethriza Hanum (2015) dengan mengolah data prioritas kriteria pemilihan supplier yang bertujuan untuk mendapatkan jenis supplier yang compatible. Hasil dari penelitiannya menggunakan metode AHP adalah 3 jenis supplier yang dianggap paling compatible yaitu Supplier Imported Steel Coil, Supplier Imported and local part dan Supplier Local Alumunium. Menurut Hanum (2015) sering munculnya potensi masalah dalam pembelian material didalam pemilihan supplier dapat diatasi dengan metode AHP untuk mengidentifikasi dan menentukan prioritas kriteria sehingga dapat menentukan Best Supplier. 
Djoko Wijono (2015) menggunakan metode AHP untuk membantu pengambilan keputusan dalam menentukan pemilihan lokasi untuk pelaksanaan program ekonomi produktif SAKOFA. Penggunaan multikriteria dalam pemilihan lokasi menjadi lebih mudah sehingga membantu pihak manajemen Dompet Dhuafa Yogyakarta.

Ida Ayu Utari Ananda Putri (2016) PT. XYZ menggunakan metode AHP dalam menentukan kriteria yang menjadi prioritas perusahaan dalam mencari kandidat program management trainee. Ditemukan kriteria yang menjadi prioritas adalah pendidikan terakhir, kemampuan manajerial, kemampuan personal, kemampuan teknis, dan terakhir pengalaman kerja. Dalam penelitian ini, peneliti menggunakan metode yang sama yaitu Analytical Hierarchy Process untuk aplikasi pada penentuan prioritas program kerja pada PT. Garuda Indonesia Cargo.

\section{METODE PENELITIAN}

Peneliti menggunakan beberapa metode pengumpulan data sebagai berikut :

1. Wawancara (Interview)

Wawancara menurut Nazir (1988) adalah proses memperoleh keterangan untuk tujuan penelitian dengan cara tanya jawab sambil bertatap muka antara si penanya atau pewawancara dengan si penjawab atau responden dengan menggunakan alat yang dinamakan interview guide (panduan wawancara). Tujuan utama dari wawancara ini adalah untuk memperoleh pangetahuan yang mendalam dengan mendengar sekelompok orang dari pasar sasaran yang tepat untuk membicarakan isu yang diamati dengan peneliti. (Malhotra, 1993) Hasil dalam tahap wawancara ini adalah matrik yang akan dikemudian dikembangkan menjadi kuisioner.

2. Penyebaran Angket (kuesioner)

Menurut Sugiyono (2011) kuesioner merupakan teknik pengumpulan data yang dilakukan dengan cara memberi seperangkat pertanyaan atau pernyataan tertulis kepada responden untuk dijawab. Dalam penelitian ini, peneliti menyebarkan kuesioner yang ditujukan kepada manajemen PT. Garuda Indonesia Cargo.

3. Pengolahan dan Analisis Data ( AHP)

Metode AHP (Analitycal Hierarchy Process) merupakan metode yang dikembangkan oleh Thomas L. Saaty sekitar tahun1970, metode ini merupakan sebuah kerangka untuk pengambilan keputusan dengan efektif atas persoalan yang kompleks. Ada 4 prinsip dasar yang digunakan untuk memecahkan persoalan AHP ini, yaitu membuat hirarki, penilaian kriteria dan alternatif, menentukan prioritas, dan mengkur konsistensi (Kusrini, 2007). Apabila suatu permasalahan 
pengambilan keputusan ingin diselesaikan dengan menggunakan metode AHP, permasalahan tersebut perlu dimodelkan dengan tiga hirarki umum, yakni tujuan, kriteria (termasuk sub-sub kriteria), dan alternatif. Konsep dasar dari AHP sebenarnya terletak dari penggunaan pairwise comparison matrix (matrix perbandingan berpasangan) untuk dapat mengahasilkan bobot relatif antar kriteria maupun alternatif. Suatu kriteria akan dibandingkan dengan kriteria lainnya dalam hal seberapa penting terhadap pencapaian tujuaannya. Untuk menentukan matrix perbandingan berpasangan dapat menggunakan nilai atau skala perbandingan yang biasa digunakan untuk mengukurnya yaitu dengan menggunakan skala 1 sampai 9.

Tabel 1. Skala banding dalam AHP

\begin{tabular}{|c|l|}
\hline Tingkat Kepentingan & \multicolumn{1}{|c|}{ Definisi } \\
\hline 1 & Sama penting \\
\hline 3 & Sedikit lebih penting \\
\hline 5 & Sangat penting \\
\hline 7 & Jelas lebih penting \\
\hline 9 & $\begin{array}{l}\text { Mutlak lebih penting } \\
\text { Apabila ragu-ragu nilai antar } \\
\text { dua nilai yang berdekatan }\end{array}$ \\
\hline $2,4,6,8$ & \begin{tabular}{l} 
\\
\hline
\end{tabular} \\
\hline
\end{tabular}

\subsection{LANGKAH - LANGKAH AHP}

Menurut Tominanto (2012), Langkah - langkah dalam menggunakan metode AHP adalah sebagi berikut :

1. Menyusun hirarki dari permasalahan yang dihadapi,

2. Menentukan prioritas elemen, 
a. Langkah pertama dalam menentukan prioritas elemen adalah membuat perbandingan berpasangan, yaitu membandingkan elemen secara berpasangan sesuai kriteria yang di berikan dengan menggunakan bentuk matriks.

b. Mengisi matrik perbandingan berpasangan yaitu dengan menggunakan bilangan untuk merepresentasikan kepentingan relatif dari satu elemen.

c. Pertimbangan-pertimbangan terhadap perbandingan berpasangan di sintesis untuk memperoleh keseluruhan prioritas dengan tahap:

1) Menjumlahkan nilai-nilai dari setiap kolom pada matriks,

2) Membagi setiap nilai dari kolom dengan total kolom yang bersangkutan untuk memperoleh normalisasi matriks,

3) Menjumlahkan nilai dari setiap matriks dan membaginya dengan jumlah elemen untuk mendapatkan nilai rata-rata,

4) Mengukur konsistensi dengan langkah:

a) Mengkalikan nilai pada kolom pertama dengan prioritas relatif elemen pertama, nilai pada kolom kedua dengan prioritas relative elemen kedua, dan seterusnya,

b) Menjumlahkan setiap baris,

c) Hasil dari penjumlahan baris dibagikan dengan elemen prioritas relatif yang bersangkutan,

d) Membagi hasil diatas dengan banyak elemen yang ada, hasilnya disebut eigen value $\left(\lambda_{\max }\right)$

e) Menghitung indeks konsistensi (consistency index) dengan rumus : $\mathrm{CI}=\frac{\left(\lambda_{\max }-n\right)}{n}$

$$
\begin{aligned}
& \mathrm{CI}: \text { Consistensi Index } \\
& \lambda_{\text {max }}: \text { Eigen Value } \\
& \mathrm{N} \quad: \text { Banyak elemen }
\end{aligned}
$$

f) Menghitung konsistensi ratio (CR) dengan rumus :

$\mathrm{CR}=\frac{C I}{R C}$

CR : Consistency Ratio

CI : Consistency Index

RC: Random Consistency Jika CR $<0,1$ maka nilai perbandingan berpasangan pada matriks kriteria yang diberikan konsistensi. Jika $\mathrm{CR} \geq 0,1$ maka nilai perbandingan 
berpasangan pada matriks criteria yang diberikan tidak konsisten. Sehingga jika tidak konsisten, maka pengisian nilai - nilai pada matriks berpasangan pada unsure criteria maupun alternatif harus diulang,

g) Hasil akhir berupa prioritas global sebagai nilai yang digunakan oleh pengambil keputusan berdasarkan nilai yang tertinggi.

\section{HASIL DAN PEMBAHASAN}

Dalam menjalankan penelitian ini, proses pengumpulan data dilakukan pada departemen garuda Indonesia cargo khususnya pada cargo domestik. Wawancara dilakukan untuk menghasilkan struktur matrik yang akan di kembangkan sebagai kuisioer AHP. Matrik Analytic Hieranchy Process dari penelitian ini terdapat pada gambar 1.

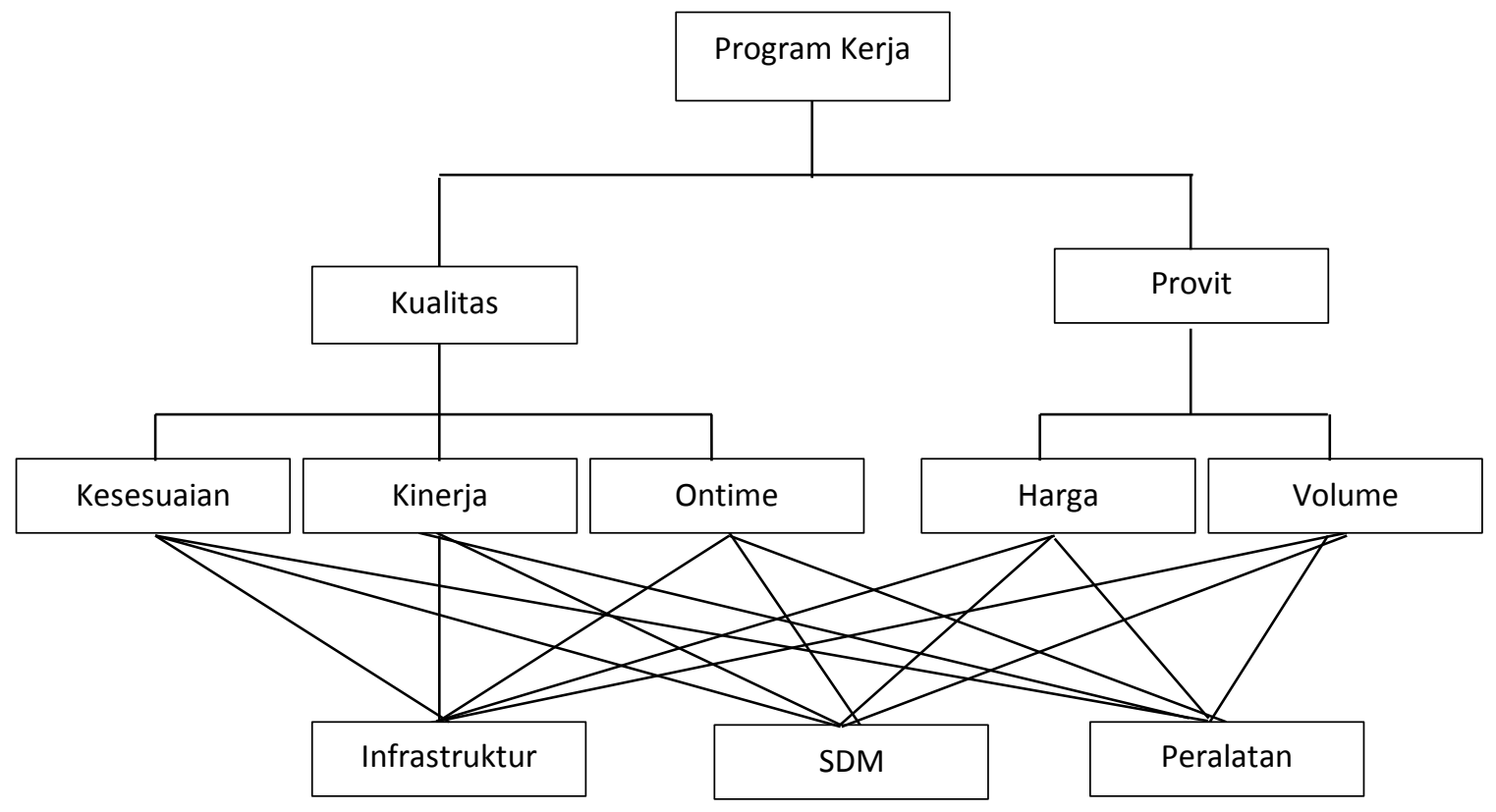

Gambar 1. Matrik Kuisioner AHP

Langkah berikutnya dalam penelitian ini adalah menyebarkan kuisioner kepada manajemen PT garuda Indonesia Cargo. Setelah menghitung rekapitulasi dari kuisioner, maka selanjutnya data hasil kuisioner diolah menggunakan metode AHP, yang diawali dengan pembobotan nilai kriteria utama, dilanjut dengan pembobotan nilai sub.kriteria dan yang terakhir adalah pembobotan nilai program kerja terhadap sub.kriteria. Hasil dari pengolahan data AHP dapat dilihat pada tabel 1. 
Tabel. 1 Tabulasi Nilai Global

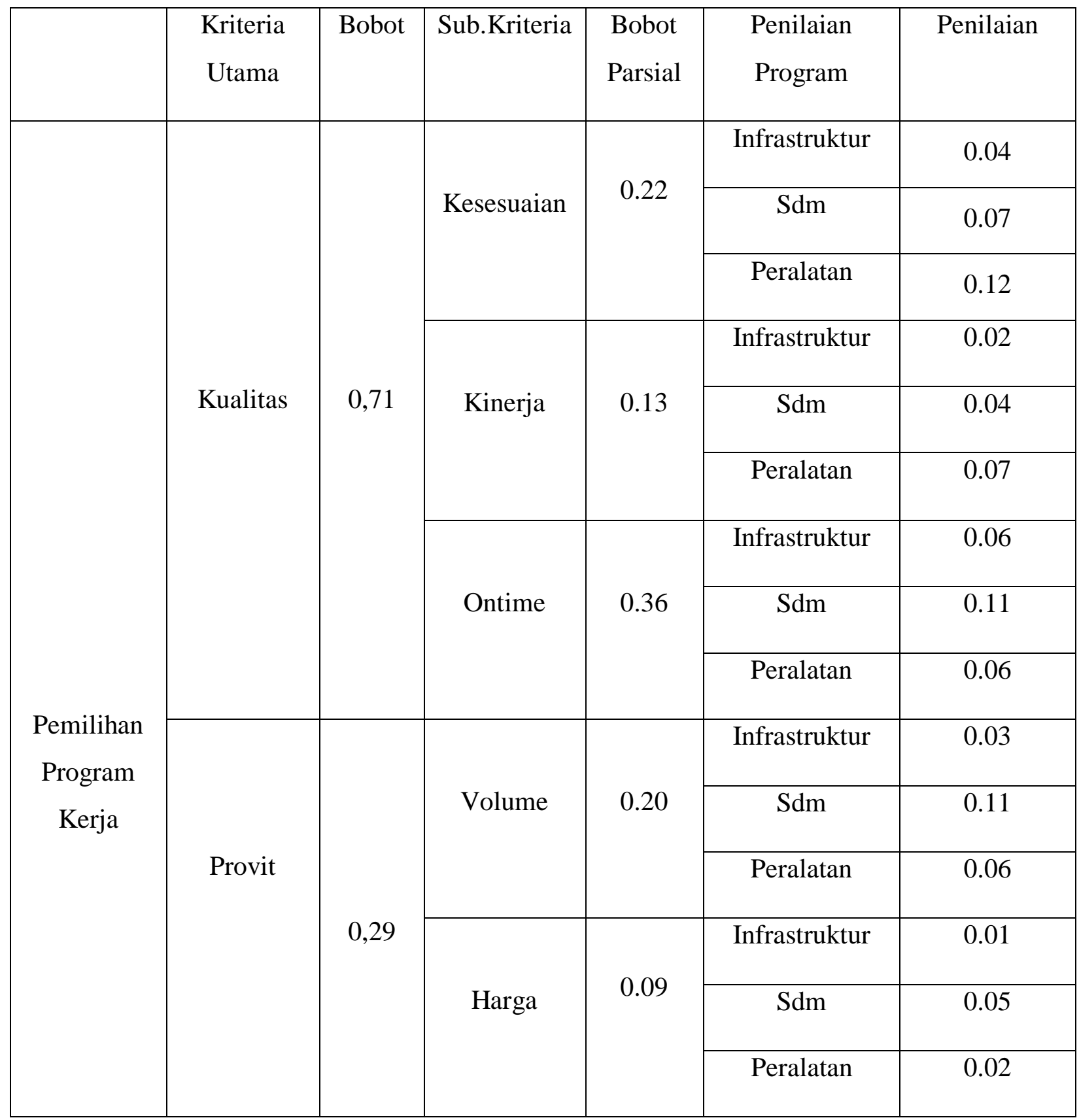

Setelah menghitung nilai global pada tabel 1, maka kita menghitung bobot supplier secara keseluruhan, dengan cara menjumlahkan nilai global priority vector, berikut adalah hasil penjumlahan dari pembobotan nilai global dari program kerja pada gambar 2. 


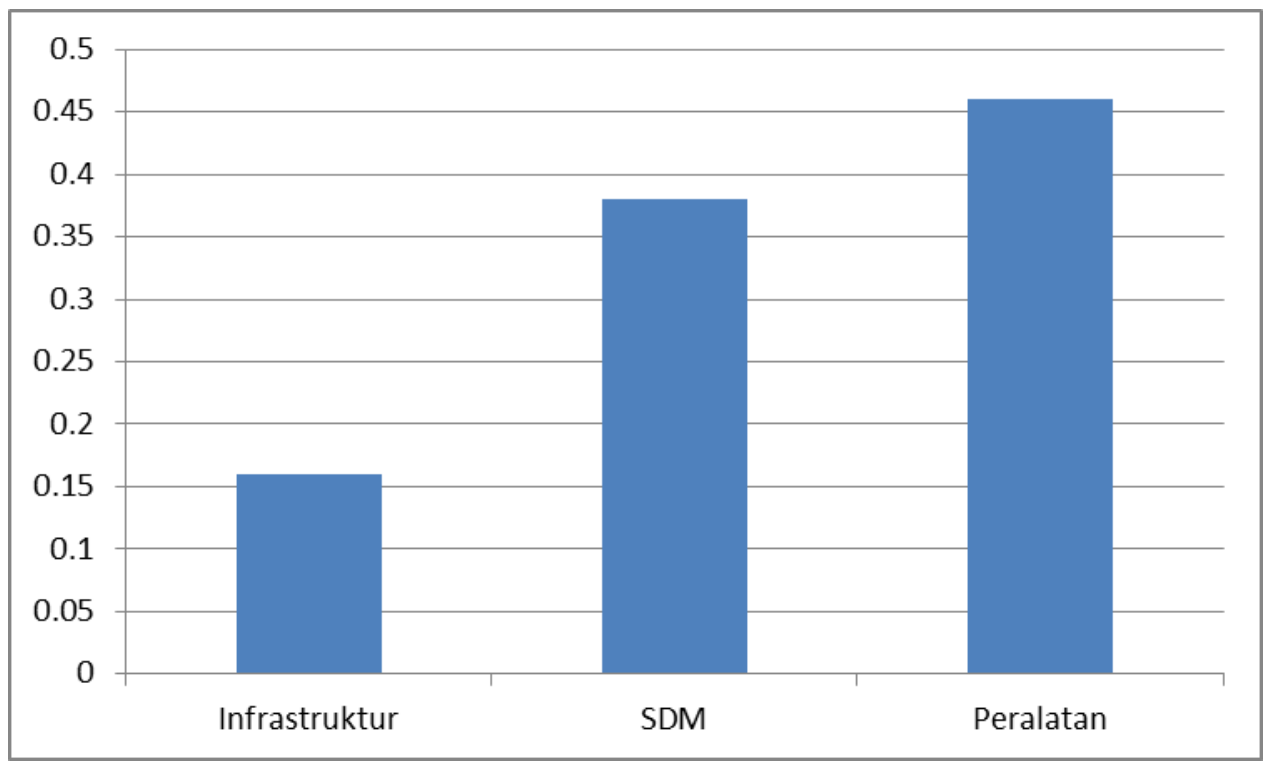

Gambar 2. Hasil Prioritas Program Kerja

\section{KESIMPULAN}

1. Setelah dilakukan penelitian ini dan analisa dengan menggunakan metode Analitycal Hierarchy Process (AHP) didapatkan hasil urutan dari masing-masing kriteria tertinggi sampai terendah dan yang mendapatkan hasil bobot tertinggi adalah kriteria Kualitas dengan nilai bobot akhir 0.71 setelah itu diikuti oleh kriteria provit dengan bobot hasil akhir 0.29.

2. Setelah pembobotan kriteria didapatkan, alternative optimal yang trerpilih adalah Peralatan dengan nilai bobot 0.46 , dan diikuti oleh SDM dengan nilai bobot 0.38 , Selanjutnya yaitu Infrastruktur dengan nilai bobot akhir 0.16

\section{SARAN}

Berdasarkan hasil dan pembahasan diatas bahwa penggunaan metode AHP dinilai sangat berguna dalam memecahkan masalah multi kriteria dalam menentukan dan mendukung pemilihan keputusan. Oleh karena itu kedepannya peneliti bisa memakai metode AHP untuk mengetahui lebih banyak bobot nilai dari masing - masing kriteria baru sehingga mendapatkan kriteria yang lebih relevan dan kompetitif untuk menentukan program kerja yang tepat sesuai dengan kebutuhan perusahaan. Selain itu untuk penelitian selanjutnya bisa menjabarkan program kerja secara lebih terinci agar bisa lebih mudah diimplementasikan oleh perusahaan. 


\section{DAFTAR PUSTAKA}

[1] Hanum, Bethriza,. 2015. Analisa pemilihan supplier sebagai komponen pendukung produksi PT.XYZ menggunakan metode Analytic Hierarchy Process (AHP) Vol 9, No 2 Jurnal Pasti

[2] Kusrini Dan Gole, A W. 2007. Sistem Pendukung Keputusan Penentuan Prestasi Pegawai Nakertrans Sumba Barat Di Waikabubak. SNATI 2007. ISSN : 1907 - 5022. Hal D-47 s/d D-52

[3] Kustian, Nunu,. 2016. Penentuan dalam pemilihan jasa pengiriman barang transaksi $E-$ Commerce online. Jurnal of Applied Business and Economics, Vol 2 nomor 4 Juni 2016

[4] Malhotra, K. Naresh, 1993, Marketing Research, Prencintice Hall, New Jersey

[5] Nakatani., 2011. A web analytics tool selection method : an analytical hierarchy process approach. Internet research, Vol. 21 Issue : 2, pp. $171-186$

[6] Nazir, Mohammad., 1988. Metode Penelitian. Graha Indonesia. Jakarta (1999 : 51)

[7] Putri, Ida Ayu Utari Ananda, Dkk,. 2016. Penentuan prioritas kriteria pemilihan kandidat program Management trainee pada PT. XYZ dengan metode Analytical Hierarchy Process (AHP), e-Proceeding of Engineering : Vol. 3 No. 3 December 2016

[8] Saaty, Thomas L., 1980. The Analytic Hierarchy Process, McGraw-Hill, New York

[9] Sugiyono. 2011. Metode Penelitian Kuantitatif Kualitatif dan R \& D. Bandung : Alfabeta.

[10] Tominanto,. 2012. Sistem Pendukung Keputusan dengan Metode Analytical Hierarchy Process (AHP) untuk Penentuan Prestasi Kinerja Dokter pada RSUD.Sukoharjo, Jurnal Infokes, Vol 2 No 1, APIKES Citra Medika Surakarta

[11] Wijono Djoko, idham ibty,. 2015. Penggunaan metode Analytical Hierarchy Process dalam pengambilan keputusan penentuan prioritas program kerja dompet dhuafa yogyakarta metode AHP volume 16,nomor 1, juli 2015 